\title{
Analysis on the Meaning of Teaching with Dialectical Negation
}

\author{
Fujiang Sun \\ Department of Political Theory \\ University of International Relations \\ Beijing, China 100091
}

\begin{abstract}
The unification of affirmation and negation of things can reach if we overcome and retain different factors of things or the different trends or properties of the same factor. Understanding that negation is the "unification of retaining and overcoming" can train students' ability and skill of dialectical thinking; application of negation helps college students to form life wisdom and broad mind of "developing themselves and accepting others"; learning negation helps students to "find the direction or entry point for development of themselves or things".
\end{abstract}

Keywords - teachers; students; overcome; retain; negation

\section{INTRODUCTION}

Dialectical negation is a difficulty in teaching principles of philosophy. Many students say the contents of negation are too abstract and they fail to grasp the essential connotation of negative concepts but only remember of definition of it at best. Students don't understand the significance or effects of learning negation. They may forget the knowledge after learning it especially after the examination, let along applying it in learning life and work. Some teachers think the discussion on the significance of learning negation in teaching materials is inadequate and needs teachers to excavate further. It is difficult to reach a consensus because different people hold different opinions and feelings.

This paper assumes students pursue the maximum benefits through learning and benefit through interaction between teaching and learning. Teachers' actions influence or restrict students' benefits. According to the existing research results [1-10], from the perspective of interaction between teachers and students in teaching, analyze the significance for students to learn negation and how teachers maximize students' benefits through teaching.

II. UNDERSTANDING AND APPLYING "NEGATION IS THE UNIFICATION OF RETAINING AND OVERCOMING" CAN TRAIN STUDENTS' DIALECTICAL THINKING AND SKILLS

The connotation and contents of dialectical negation will be introduced first. Negation is the aspect or factor in existing things that makes it die out, also the development direction of things in the future; negation is the period or state when old things develop into new things; negation is the links related to old things when old things develop into new things; negation is the result of self-negation of things instead of exogenous process; negation is sublation or overcoming and retaining, the unification of affirmation and negation.

According to teaching practice, students have difficulty in understanding even fail to understand "negation is the unification of overcoming and retaining" in the dialectical negation. Without ability of dialectical thinking, students cannot understand the opinion. They will ask: Overcoming isn't retaining, and retaining isn't overcoming. Can we overcome and retain at the same time? How to overcome and retain at the same time? Teachers are required to explain it to them so that they can truly understand it. Training students' dialectical thinking through this knowledge point can improve their thinking quality and make students form maximum return on this problem. Teachers play a crucial role in it because they know it won't have substantial effects if students only remember the knowledge point.

How to overcome and retain at the same time? How can teachers make students truly grasp the knowledge and skill and obtain the maximum benefits? According to teachers' research and teaching practice, if teachers teach students "overcome or retain a part of it" so that we can overcome and retain at the same time, students can understand the connotation and skills in unification of overcoming and retaining through analysis of cases. For example, China brings in market economy thought and mode of western countries. It is a way or mechanism to produce or provide service according to requirements of consumers. Producers or providers of service cater to the requirements of consumers so that they can gain more benefits, otherwise benefits will loss. Market model requires laborers to give their subjective initiative into full play and accurately judge and meet consumers' requirements, in order to maximize self-interest in the competition with other laborers. Market model makes laborers provide more products or service for the society and makes corresponding laborers especially laborers with high efficiency get more benefits, and breaks the situation under the condition of planned economy that laborers "get the same results no matter how hard they work". It plays the role of interest motive force to arouse the enthusiasm of laborers in social development especially economic development. Laborers see the excitation effects of 
more pay for more work, so that they try every means to improve labor skills and quality. Therefore, the social productivity of the whole society improves and the country will develop further correspondingly. However, in the operation of market economy, some people harm others to benefit themselves for personal interests. It indicates market economy has advantages and disadvantages. How can we take an attitude? Naturally, we must adopt its good points and avoid its shortcomings. It insists the method of dialectical unity through retaining the good points and avoiding shortcomings of market economic system.

In reality, things have many factors. The reason why students fail to understand "overcome and retain" or affirm and negate things is that they think we overcome and retain the same element in things. It is illogical and incomprehensible to affirm and negate the same factor in things. It doesn't overcome and retain the same factor in things in dialectical negation. In dialectical negation, people affirm and negate or overcome and retain different factors or aspects in things. The negation of the same factor in the same thing also overcomes and retains different properties of the factor. For example, how to treat classmates? Classmates have many strong points and shortcomings. They are unity of strong points and shortcomings. Teachers or administrators must adopt their good points and avoid or overcome their shortcomings instead of one-sidedly seeing their shortcomings, failing to see or being unwilling to see or blindly slandering their strong points. How to regard ourselves? We must objectively analyze our strong points and shortcomings instead of only seeing our shorts comings and neglecting our shortcomings. Students should truly understand the thinking method of "retaining and overcoming things" with the explanation of these cases.

Another problem should be clear to truly grasp the method and skill. Does the thinking method or skill have universality? It requires students to propose. Of course, teachers are required to explain correspondingly: Things are unity of multiple properties. Different properties play different roles in the development of things. The degrees of properties to take effect in different periods when things change are different. Generally speaking, we should retain factors that have positive effects on existence and development of things, and we should overcome factors that have negative effects on development of things. It requires subjects to judge whether factors of things have positive or negative effects on development of things according to their development needs. Students will understand the knowledge point without difficulty and know how to operate the thinking skill if corresponding case explanation is provided. Students know we should roundly analyze things, see positive factors and negative factors and insist the unification of affirmation and negation. At this time, students have the ability of dialectical thinking or have an opportunity to train ability of dialectical thinking. If teachers train students like this for a long time, students will develop ability of dialectical thinking and form corresponding thinking ability. In this way, students will get learning benefits through teachers' service.

\section{Application OF NEGAtion Helps CollegE} STUDENTS TO FORM LIFE WISDOM AND BROAD MIND OF "DEVEloping THEMSELVES AND ACCEPTING OTHERS"

Students have got maximum benefits and teachers have completed the teaching of this knowledge point when teachers' explanation of the dialectical negation reaches the above degree. However, if the interaction between teachers and students can continue and teachers hope students can get more benefits, teachers can explore other values or significance of the knowledge point on students. According to teaching researches and practice, in the interaction between teachers and students, students will get more benefits if teachers propose grasping this knowledge helps college students to get life wisdom and broad mind of "accepting others and developing themselves" and method to cultivate their moral character.

We must admit the existence of factors, properties and aspects of things when analyzing things through the thinking method of unification of affirmation and negation, so that we can analyze objectively and roundly. Naturally, we can judge the aspects of things that we retain and overcome through distinguishing different effects of properties on existence and development of things. The problem is: what is the purpose and significance for us to analyze positive and negative effects of properties and aspects of things. For ourselves, the purpose of analysis is to improve ourselves or overcome our shortcomings through application of positive or affirmative aspects of things. According to the contrastive analysis on social productive forces of China and America before the reform and opening up, high technology, technical equipment, advanced management experience and high quality laborers in American society are factors superior to us and deserving our affirmation. Of course, negative things also exist and we must overcome. In the process of opening to the outside world, we analyze factors of foreign countries and propose policies as well as introduce technology, equipment, talents and market model of foreign countries to overcome or make up for the backward productivity factors in our country and accelerate the development of Chinese society.

Therefore, it is not enough for us to see others' strong points and shortcomings. We should learn from others' strong points to offset our weakness, in order to make progress continuously. Moreover, in this process, we must inevitably admit and accept others' strong points and tolerate their shortcomings, so that we can form a broad mind and improve ourselves.

\section{LEARNING NEGATION HELPS STUDENTS TO "FIND DIRECTION OR OBJECTIVES FOR THE DEVELOPMENT OF THEMSELVES OR THINGS"}

In the interaction between teachers and students, if teachers further propose learning this knowledge and skill makes people especially college students "find direction or entry point for the development of themselves or things", students will get more benefits. How do we treat the shortcomings of things? For example, how do college students treat shortcomings of themselves and others? 
Should they totally abandon? Should they negate shortcomings? Can we find things conducive to us? Generally speaking, shortcomings will be overcome and abandoned. However, in materialistic dialectics, negation of things means negating an aspect of it that represents the future and direction of things. The abandonment of negative aspect in things doesn't mean ruining the future of things. Overcoming shortcomings means turning it into aspects favorable for things themselves or other things. Things get better if defects are transformed into good aspects. It is also called things get progressive development.

Of course, new negative aspects will appear after the negative aspects of the current things are transformed into affirmative aspects of new things. At that time, we can transform new negative aspects into affirmative aspects of the newest things. Things get further development. In this sense, we call negative aspects become the direction for the development of things. For example, before opening to the outside world, backward productivity becomes an important problem that restricts social development and an undeniable shortcoming of our country. We begin from it namely the negative aspect. In the process of opening to the outside world, we first bring technical equipment and talents even capitals from foreign countries in special economic zones and carry out internal reform especially the reform of college entrance examination system to train high quality talents. Talent transfer policy is implemented to attract large numbers of high quality laborers to construct in special economic zones. It improves the average quality of laborers and the efficiency that laborers use tools. After years of construction, people's living standard improves. The productivity of domestic society especially of the special economic zones improves. We overcome the defects. New defects appear after old defects are overcome. For example, the level of productive forces in special economic zones improves, but we fail to grasp the core technology introduced We imitate products and services in foreign countries. Of course, we can introduce new technology again and imitate and develop, but it increases cost and makes us lag behind foreign countries because they won't export the newest technology to China. In a word, the capacity of independent innovation is inadequate. Therefore, we must digest and create new technology when bringing in technology of foreign country. As a result, various research and development centers of technology are established in special economic zones. Special economic zones will realize real independent development with its own characteristics and innovation if this problem is solved. The country will develop continuously if we ceaselessly find out defects or negative aspects in development and solve these problems.

To sum up, once college students grasp the thinking method or skill, they can analyze problems of their own in learning or work, and take the problem as new direction or breakthrough point and solve problems to promote the development of them. It realizes the guiding function of philosophical theory and refers to the specific benefit through learning negation.

\section{CONCLUSION}

Analyzing the negation or defects of things and continuously overcoming defects helps students to establish the direction and objectives for the development of themselves or things. It can develop students' thinking method or skill of roundly looking at the problem through training them to affirm or negate different factors or aspects in things or overcome and retain different properties of the same factor in the same thing. Students can improve selfquality and form broad mind to tolerate others' shortcomings through analyzing factors and properties of things and the positive and negative effects, absorbing positive aspects of things and consciously overcoming self-insufficiency.

\section{REFERENCES}

[1] Lin Yuan. Does Dialectical Negation Mean Things "Deny Themselves"? Theory Monthly, the 8th Issue in 1987

[2] Huang Zongli, Yuan Endi. Dialectical Negation Is the Unification of Utter Negation and Partial Negation, Journal of Jiujiang University, the 5th Issue in 2008

[3] Gao Qingchuan. Mechanism of Dialectical Negation and Its Application in Practice, Journal of Anhui University, the 2nd Issue in 1990

[4] Zhou Linzhang. Reflection on Neither Total Affirmation Nor Tota Repudiation, Journal of Anhui University, the 5th Issue of the 25th Volume in 2001

[5] Dai Anliang. Recognition on Dialectical Negation, Exploration, the 2nd Issue in 1995

[6] Yu Chaoqing, Fang Shinan. Thinking on Dialectical Negation, Journal of Suzhou University, the 3rd Issue in 1983

[7] Yu Yude. Dialectical Negation and Its Basic Mode, Journal of Liaoning University, the 5th Issue in 1980

[8] Lu Qingshan. Discussion on Three Links and Twice Negation, Journal of Foshan University, the 1st Issue of the 14th Volume in 1996

[9] Zhang Kaize. Discussion on the Theoretical Error of the Existing Negation, Theory and Reform, the 4th Issue in 1998

[10] Luo Huihuang. Opinions on Explaining Dialectical Negation in Teaching, New Curriculum Research, the 3rd Issue in 2010 